\title{
Modulação dos efeitos citotóxicos e mutagênicos do paracetamol pelo suco de caju e cajuína em meristemas de raízes de allium cepa
}

\author{
Modulation of the cytotoxic and mutagenic effects of paracetamol by caju and cajuína juice \\ in allium cepa root merystems
}

\author{
Modulación de efectos citotóxicos y mutagénicos de paracetamol por cashew jugo y \\ cajuina en allium cepa meristema de raíz
}

Francisca Ires da Silva Santos ${ }^{1}$, Renata Kelly dos Santos e Silva ${ }^{1}$, Marlene Gomes de Farias ${ }^{1}$, David de Sousa Carvalho', Layde de Sousa Corrêa ${ }^{1}$, Athanara Alves de Sousa ${ }^{1}$, Taline Alves Nobre ${ }^{1}$, Paloma Alves Ferreira Lima ${ }^{1}$, Ana Rafaela Silva Pereira ${ }^{1}$, Maria do Perpetuo Socorro de Sousa Coêlho', Glauto Tuquarre Melo Nascimento', Victor Alves de Oliveira ${ }^{1}$, Felipe Calvalcanti Carneiro da Silva ${ }^{1}$, João Marcelo de Castro e Sousa ${ }^{1 *}$, Ana Amélia de Carvalho Melo Cavalcante ${ }^{1}$.

\section{RESUMO}

Objetivo: Avaliar a capacidade moduladora do suco de caju e cajuína diante dos efeitos toxicogenéticos do paracetamol, utilizando o sistema teste vegetal Allium cepa. Métodos: Grupos de tratamentos: Controle Negativo (água destilada - AD); Grupo 2 (10 ml de suco de caju + $30 \mathrm{ml}$ AD), Grupo 3 (10 ml de cajuína + 30 $\mathrm{ml} \mathrm{AD}$ ); Grupo 4 (10 ml de suco de caju + $30 \mathrm{ml}$ de CP); Grupo 5 (10 ml de cajuína diluído com $30 \mathrm{ml}$ de CP); e Controle Positivo $(40 \mathrm{ml}$ de paracetamol $0,3 \mathrm{mg} / \mathrm{ml}$ - CP). Utilizados cinco bulbos por tratamento, enraizadas, e transferida para suas respectivas soluções. As radículas foram coletadas e fixadas em ácido acético (3:1) após os tempos de 24 e 48 horas de exposição. As lâminas foram coradas com orceína acética a $2 \%$. Resultados: Sugere-se que compostos bioativos estejam presentes no suco de caju e sua derivação cajuína, possuindo capacidade de inibir a formação de alterações mutagênicas, causadas pelo fármaco utilizado durante o estudo, a partir da observação do aumento do Índice Mitótico e redução das Alterações Cromossômicas. Conclusão: Os dados encontrados mostraram que o suco de caju e cajuína modularam os efeitos toxicogenéticos do paracetamol, interferindo na mutagênese induzida pelo fármaco.

Palavras-Chaves: Anacardium occidentale, Vitamina C, Radicais livres.

\begin{abstract}
Objective: To evaluate the modulating capacity of cashew and cashew apple juice against the toxicogenetic effects of paracetamol, using the Allium cepa test system. Methods: Treatment groups: Negative Control (distilled water - DW); Positive Control (40mg paracetamol 0.3mg / ml - CP); Group 2 (10 ml cashew apple juice $+30 \mathrm{ml} \mathrm{DW})$; Group 3 (10 ml cashew apple juice $+30 \mathrm{ml} \mathrm{DW})$; Group 4 (10 ml cashew apple juice +30 $\mathrm{ml} \mathrm{CP}$ ) and Group $5(10 \mathrm{ml}$ cashew nuts diluted with $30 \mathrm{ml} \mathrm{CP})$. It was used five bulbs per treatment, rooted, and transferred to their respective solutions. The rootlets were collected and fixed in acetic acid (3:1) after 24 and 48 hours of exposure. The slides were stained with $2 \%$ acetic orcein. Results: It is suggested that bioactive compounds are present in cashew apple juice and its cashew derivation, having ability to inhibit the formation of mutagenic changes caused by the drug used during the study, from the observation of the increase of the Mitotic Index and reduction of the Chromosomal Changes. Conclusion: The data showed that cashew and cashew apple juice modulated the toxicogenetic effects of acetaminophen, interfering with drug induced mutagenesis.
\end{abstract}

Keywords: Anacardium occidentale, Vitamin C, Free radicals.

${ }^{1}$ Universidade Federal do Piauí (UFPI), Teresina-PI, Brasil. *E-mail: j.marcelo@ufpi.edu.br

SUBMETIDO EM: 2/2020

ACEITO EM: 2/2020

PUBLICADO EM: 4/2020 
RESUMEN

Objetivo: Evaluar la capacidad de modulación del anacardo y el jugo de anacardo contra los efectos toxicogenéticos del paracetamol, utilizando el sistema de prueba de plantas Allium cepa. Métodos: Grupos de tratamiento: Control negativo (agua destilada - AD); Grupo 2 (10 ml de jugo de anacardo $+30 \mathrm{ml} A D$ ), Grupo 3 (10 ml de jugo de anacardo $+30 \mathrm{ml} \mathrm{AD}$ ); Grupo 4 (10 ml de jugo de anacardo $+30 \mathrm{ml}$ de PC); Grupo 5 (10 ml de anacardos diluidos con $30 \mathrm{ml}$ de PC); y control positivo (40 mg de paracetamol $0,3 \mathrm{mg} / \mathrm{ml})$. Usó cinco focos por tratamiento, enraizados y transferidos a sus respectivas soluciones. Las raicillas se recogieron y se fijaron en ácido acético (3: 1) después de 24 y 48 horas de exposición. Los portaobjetos se tiñeron con orceína acética al $2 \%$. Resultados: Se sugiere que los compuestos bioactivos están presentes en el jugo de anacardo y su derivación de anacardo, que tienen la capacidad de inhibir la formación de cambios mutagénicos causados por el medicamento utilizado durante el estudio, a partir de la observación del aumento en el índice mitótico y la reducción de los cambios cromosómicos. Conclusión: Los datos encontrados mostraron que el anacardo y el jugo de anacardo modulan los efectos toxicogenéticos del acetaminofeno, lo que interfiere con la mutagénesis inducida por fármacos.

Palabras clave: Anacardium occidentale, Vitamina C, Radicales libres.

\section{INTRODUÇÃO}

As bebidas mais consumidas no Nordeste brasileiro, além do café, é o tradicional suco de caju (Anacardium occidentale) e cajuína (suco processado, confeccionado de forma caseira). Dado o crescente interesse pelo caju, processos industriais e biotecnológicos foram desenvolvidos para aumentar sua importância econômica (PIRES AM, 2010). Tanto o suco de caju quanto a cajuína podem ser considerados alimentos funcionais possuindo também efeitos metabólitos e fisiológicos que são benéficos à saúde, sendo que a eficácia e a segurança desses alimentos devem ser asseguradas por estudos científicos (SBAF, 2007).

Estudos in vitro demonstram que o suco de caju e cajuína têm atividade antimutagênica e produtos derivados, efeitos antioxidantes. A castanha de caju tem a capacidade de sequestrar radicais livres e eliminalos, característica atribuída principalmente à presença de polifenóis presentes na sua constituição química, o que tem despertado o interesse das indústrias alimentícias e farmacêuticas visando o uso do pseudofruto como uma fonte barata de antioxidantes naturais (MELO-CALVALCANTE AAC, et al., 2008).

No Brasil, a utilização de plantas medicinais está enraizada sob as culturas indígena, africana e dos imigrantes europeus, revelando importância não apenas pela eficácia terapêutica, mas também por integrar a cultura de um povo. Mesmo com os avanços tecnológicos nas práticas de saúde, o uso de plantas medicinais constitui uma das formas mais antigas bastante comum até hoje. Parte dos saberes necessários para o desenvolvimento dos medicamentos que sustentam a medicina moderna partiram do conhecimento empírico popular, incentivando pesquisas nas áreas de medicina, farmacologia e botânica (STEFANELLO S, et al., 2018).

Entre as décadas de 1940 e 1950, avanços na área de biotecnologia e o desenvolvimento de fármacos propelidos especialmente pela Segunda Guerra Mundial, marcaram o aumento progressivo do uso de medicamentos nos dias atuais (REGO SC, et al., 2015). Fatores como a forte propagação comercial e a fácil aquisição desses produtos geram nas residências brasileiras pequenas "farmácias caseiras" em que as principais classes descartadas pertencem aos analgésicos e antitérmicos, como o paracetamol (PEREIRA FGF, et al., 2019).

O paracetamol, ou acetaminofeno, faz parte do grupo de Medicamentos Isentos de Prescrição (MIPs), possui representação significativa na farmacoterapia mundial para o tratamento de doenças e sintomas brandos por seu efeito analgésico e antitérmico, por possuir venda livre, baixo custo e com um satisfatório perfil de segurança (FREITAS JAB, et al., 2017; REGO SC, et al., 2015). Entretanto, tais características cooperam para o uso indiscriminado ou irracional dos medicamentos, sendo a maior causa de intoxicação e a segunda maior de óbito por agentes tóxicos no Brasil (VIEIRA AL, et al., 2015). 
Existe uma variedade de plantas que são utilizadas para ensaios de toxicidade, no entanto uma das mais conhecidas e bem estabelecidas plantas utilizadas em bioensaios citogenéticos é o Allium cepa.

A cebola pode germinar facilmente e as raízes coletadas são simples de armazenar. Os fatores macroscópicos e microscópicos podem ser avaliados nessa espécie sem muito esforço (LIMAN R, 2013). Finalmente, é importante observar que existe uma relação entre os resultados obtidos a partir de bioensaios de plantas e outros sistemas de ensaio (FIRBAS P; AMON T, 2013; MAITI S, et al., 2016), o que aumenta a sua utilidade.

Considerando o potencial de intoxicação e relevância toxicológica dos MIPs e as propriedades do suco de caju e cajuína, o objetivo deste trabalho consiste em avaliar a capacidade moduladora do suco de caju e cajuína diante dos efeitos citotóxicos e mutagênicos do paracetamol, utilizando o sistema teste vegetal Allium cepa, amplamente utilizado para avaliar o potencial de mutagenicidade e citotoxicidade de plantas medicinais devido a sua alta sensibilidade, baixo custo, confiabilidade e excelente correlação com marcadores farmacogenéticos.

\section{MÉTODOS}

\section{Obtenções dos respectivos sucos e cajuínas alimentares e definição das concentrações.}

Os cajus e as cajuínas para realização desse estudo foram comprados na cidade de Santo Antônio de Lisboa, no interior do Piauí que se destaca produtivamente e economicamente na produção deste fruto e cajuína sendo conhecida como a Capital do Caju, apresentando grande concentração, a maior do Brasil, de área plantada com esse fruto por metro quadrado.

Os cajus foram lavados e esterilizados por imersão da fruta em etanol $70 \%$. A extração do suco foi feita por esmagamento dos pedúnculos utilizando equipamentos esterilizados, tomando-se o cuidado de obter um suco com o maior teor de polpa possível. A cajuína utilizada nos experimentos seguiu o seguinte padrão de produção: centrifugação dos frutos macerados, clarificação com gelatina, filtração e tratamento térmico (1

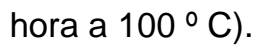

Para a realização dos experimentos, as raízes de Allium cepa distribuídas em cinco frascos foram expostas aos seguintes grupos de tratamento: Grupo 1 - Controle Negativo com água destilada; Grupo 2 - $10 \mathrm{ml}$ de suco de caju diluídas em $30 \mathrm{ml}$ água destilada, Grupo 3 - $10 \mathrm{ml}$ de cajuína diluída em $30 \mathrm{ml}$ água destilada; Grupo $4-10 \mathrm{ml}$ de suco de caju diluído com $30 \mathrm{ml}$ de controle positivo (paracetamol na concentração final de $0,3 \mathrm{mg} / \mathrm{ml}$ ); Grupo 5 - $10 \mathrm{ml}$ de cajuína diluído com $30 \mathrm{ml}$ de controle positivo (paracetamol, na concentração final de 0,3mg/ml); e Grupo 6-40ml de Controle positivo (Paracetamol, 0,3mg/ml).

Os grupos 4 e 5 foram misturados ao controle positivo para verificar a capacidade que o suco de caju e a cajuína tinham de inibir o processo mutagênico e citotóxico do Paracetamol, sendo todas estas soluções expostas por 24 e 48 horas, procedimento este denominado de tempo de exposição de 24 horas (TE 24h) e 48 horas (TE 48h).

\section{Obtenções de células meristemáticas de raízes de $A$. cepa para a análise citogenética}

Para a realização deste trabalho foram adquiridas cebolas de uma fonte comercial e colocadas para enraizar em copo descartável de $50 \mathrm{~mL}$ com água destilada, à temperatura ambiente $\left( \pm 25^{\circ} \mathrm{C}\right)$, aerada, até obtenção de raízes com cerca de 1 a $1,5 \mathrm{~cm}$ de comprimento.

Para a análise de cada tratamento foi utilizado cinco cebolas, estas foram adicionadas as soluções de cada tratamento no copo descartável sendo devidamente identificadas. As raízes foram tratadas no período de 24 e 48 horas, coletadas e depois fixadas, deixadas no período de 24 horas a temperatura de $10^{\circ} \mathrm{C}$. Sendo que as cebolas eram devolvidas a cada coleta aos seus referidos locais.

Nos frascos de cada bulbo foi colocado um volume total de $40 \mathrm{ml}$, ordenadas de acordo com cada tratamento, tendo-se o cuidado de verificar se todas as raízes estavam em contato adequado com a solução em estudo. A fixação das raízes se deu em Carnoy 3:1 (etanol: ácido acético), a temperatura ambiente, por 
24 horas. Para cada coleta de raiz, retirou-se, em média, três raízes por bulbo. Os tempos de exposição de $24 \mathrm{~h}$ e $48 \mathrm{~h}$ foram escolhidos com o intuito de se avaliar a ação destas doses em mais de um ciclo celular.

\section{Preparo, leitura das lâminas e análise dos dados}

As lâminas, em média 03 por bulbo, foram feitas seguindo o protocolo proposto por Guerra M e Souza MJ (2002). Cada lâmina foi corada com duas gotas de orceína acética a $2 \%$ e analisada em microscópio óptico, em objetiva de $40 X$.

Para cada bulbo analisou-se 1.000 células, totalizando 5.000 células para cada controle e tempo de exposição, ou seja, cinco bulbos por tratamento. Foram observadas células em interfase, prófase, metáfase, anáfase e telófase.

Foi calculado o número de células em interfase e em divisão de cada controle e tempo de exposição e determinando o índice mitótico. Avaliou-se também a ação mutagênica das doses por meio do número de células micronucleadas, de metáfases colchicínicas, pontes anafásicas e telofásicas, amplificações gênicas, células com aderências, brotos nucleares e anáfases multipolares.

\section{Análise estatística}

Os índices mitóticos calculados e as aberrações cromossômicas celulares observados foram submetidos à análise estatística. Para iniciar as análises estatísticas, foram realizados testes de normalidade (Teste de Kolmokorov-Smirnov) e homocedasticidade (Teste de Levene) para saber se seriam usados testes paramétricos ou não paramétricos para resolução dos mesmos.

Os dados se apresentaram com distribuição normal e homogênea, nesse caso, foram utilizados ANOVA unifatorial e Pós-teste de Fisher LSD. Os testes foram realizados com o programa estatístico Statistica 8.0. Em todos os testes foi considerado o nível de significância de 0,05.

\section{Cálculo da Porcentagem de Inibição}

A capacidade do suco de caju e cajuína para reduzir os danos cromossômicos causados pelo Paracetamol (Controle Positivo) foi calculada usando a seguinte fórmula: \%R = A - B=A-C, no qual \%R é a porcentagem de redução, $A$ é a frequência de alterações cromossômicas depois do tratamento com o Paracetamol, $B$ é a frequência de alterações cromossômicas depois do co-tratamento e $C$ é a frequência de alterações cromossômicas no controle negativo.

\section{RESULTADOS E DISCUSSÃO}

Nas Tabela 1, é apresentado o número de células em interfase, em diferentes fases da divisão celular e valores de índices mitóticos todos com média e desvio padrão observadas nos diferentes tratamentos com o tempo de exposição de $24 \mathrm{~h}$ e $48 \mathrm{~h}$, respectivamente.

O controle positivo (paracetamol $0,3 \mathrm{mg} / \mathrm{L}$ ) reduziu de forma significante $(p<0,05)$ o índice mitótico quando comparado com o controle negativo, mostrando sua atividade citotóxica para sistema teste vegetal. Os tratamentos com suco de caju e a cajuína separadamente não foram capazes de alterar significantemente 0 índice mitótico (IM) das células vegetais, não diferindo assim do tratamento com o controle negativo.

Já os grupos de tratamento 04 e 05 respectivamente, Caju+CP e Cajuína+CP, diferiram estatisticamente $(p<0,01)$ do tratamento com paracetamol, nesse caso, mostrando o poder anticitotóxico do suco de caju e da cajuína em reduzir o efeito citotóxico do CP utilizado (Figura 1). 
Figura 1 - Atividade anticitotóxica do suco do caju e da cajuína quando administrado juntamente com um CP utilizado em sistemas testes vegetais com TE 24h.

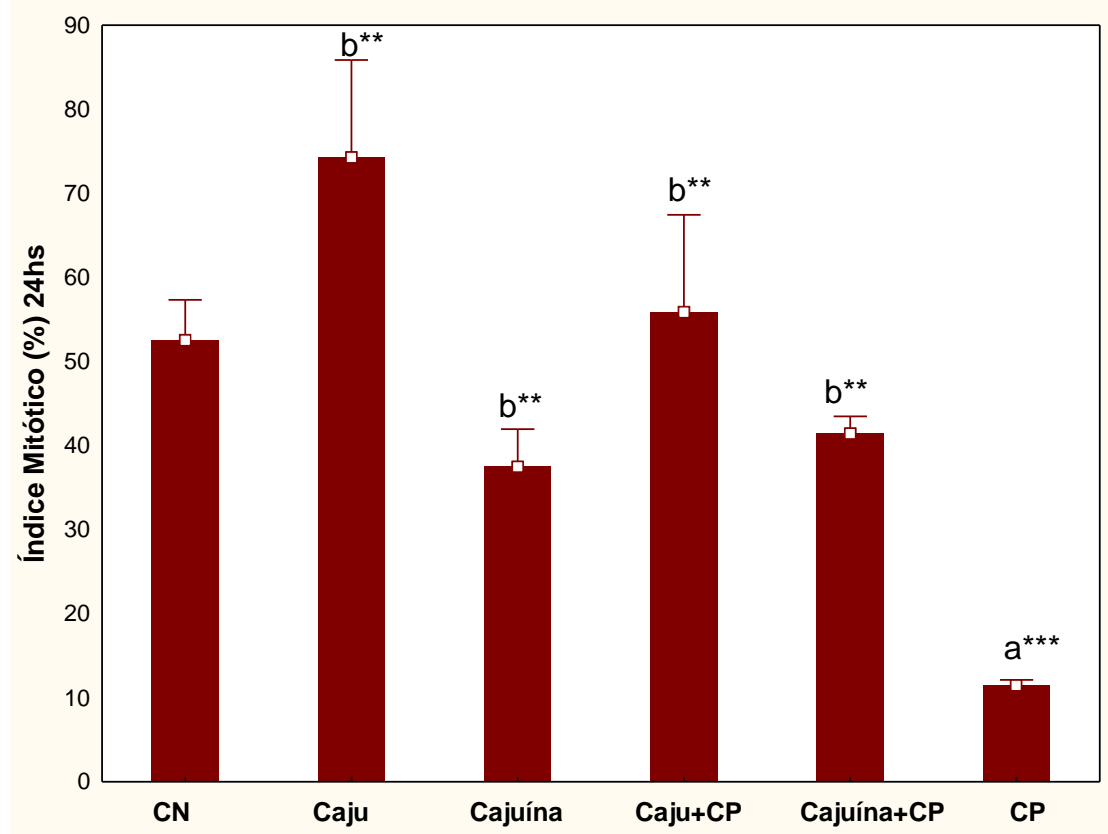

Legenda: CN - Controle negativo; CP - Controle Positivo. ANOVA unifatorial, com Pós-teste de Fisher LSD. a: Significante comparado com $C N,{ }^{* \star *} p<0,001$; b: Significante comparado com $C P,{ }^{* \star} p<0,01$.

Fonte: Santos FIS, et al., 2019.

Particularmente, para o TE 48hs, o tratamento com Cajuína + CP se mostrou estatisticamente significante $(p<0,05)$ em relação aos tratamentos dos grupos 2 (caju), 3 (cajuína) e 4 (caju+CP), porém ainda com capacidade de inibir significante a atividade citotóxica do CP (Figura 2).

Figura 2 - Atividade anticitotóxica do suco do caju e da cajuína quando administrado juntamente com um CP utilizado em sistemas testes vegetais com TE 48hs.

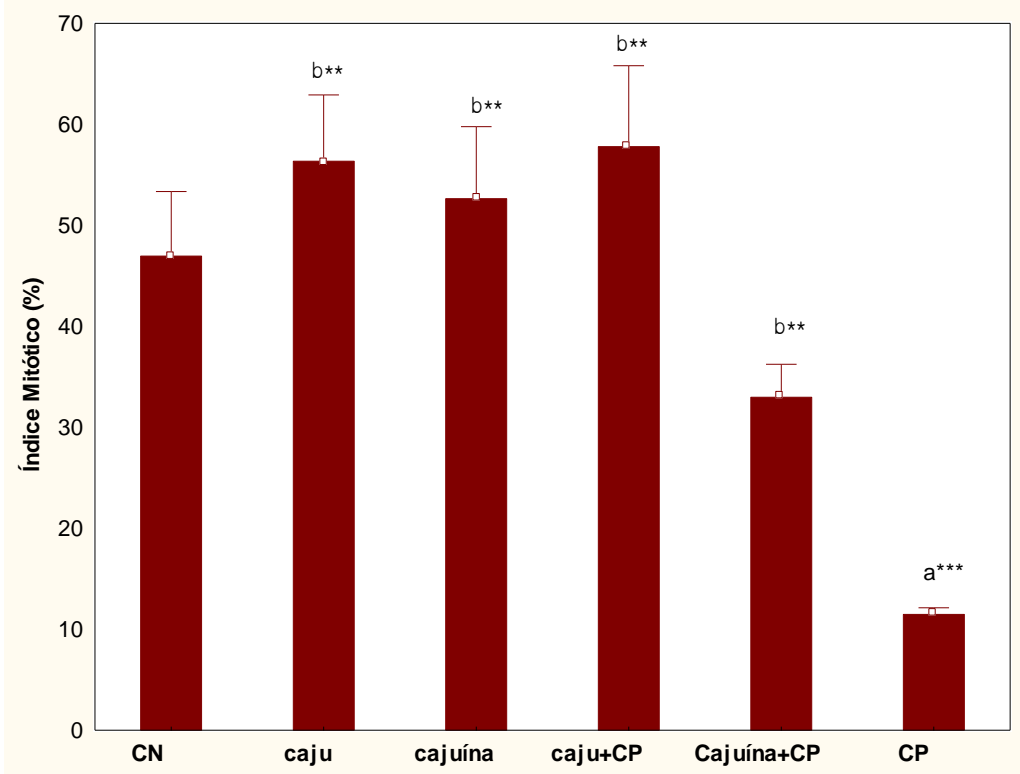

Legenda: CN - Controle negativo; CP - Controle Positivo. ANOVA unifatorial, com Pós-teste de Fisher LSD. a: Significante comparado com $C N,{ }^{* *} p<0,001 ; b$ : Significante comparado com $C P,{ }^{* *} p<0,01$.

Fonte: Santos FIS, et al., 2019. 
Tabela 1 - Número total de células em raízes de Allium cepa analisadas em diferentes tratamentos no tempo de exposição de $24 \mathrm{~h}$ e $48 \mathrm{~h}$. Foram analisadas 5.000 células para cada tratamento.

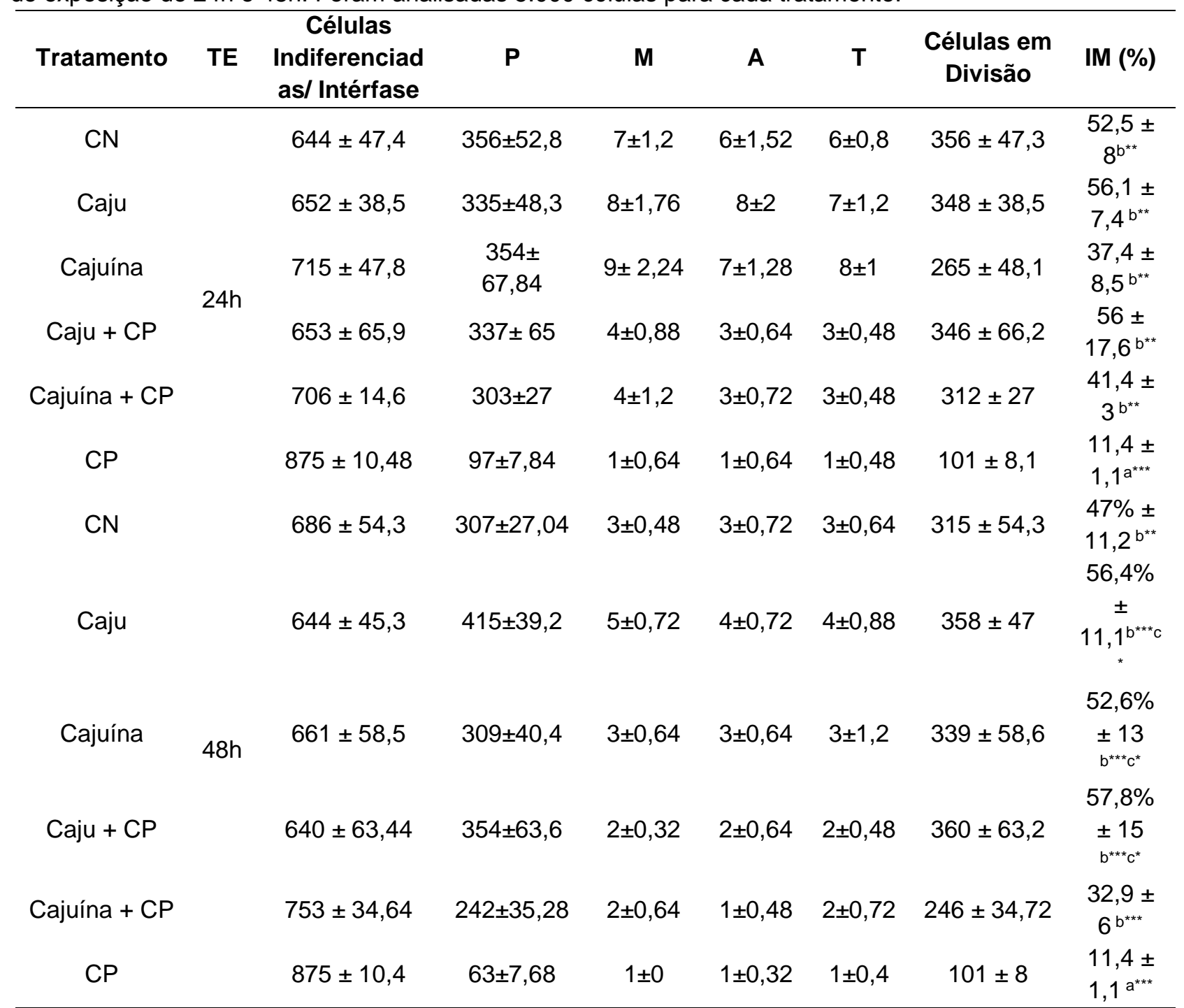

Legenda: CN - Controle negativo; CP - Controle Positivo; P - prófase; M - Metáfase; A - Anáfase; T Telófase. ANOVA unifatorial, com Pós-teste de Fisher LSD. a: Significante comparado com CN, ${ }^{* \star *} \mathrm{p}<0,001$. b: Significante comparado com $C P,{ }^{* *} p<0,01$; : Significante comparado com Cajuína $+C P,{ }^{*} p<0,05$.

Fonte: Santos FIS, et al., 2019.

Os estudos de Rego SC, et al. (2015) demonstraram que o medicamento utilizado como Controle positivo, no caso, o paracetamol, é um potente composto citotóxico e mutagênico. Trabalhos como os de Portis IG, et al. (2016) e Silva FDB, et al. (2015), utilizaram esse fármaco na concentração de $0,008 \mathrm{mg} / \mathrm{ml}$ como CP nos seus testes toxicológicos utilizando Allium cepa.

Nesse caso, o presente estudo teve como objetivo avaliar e comprovar a capacidade do suco caju e da cajuína a partir dos seus componentes bioativos de reduzir os efeitos citotóxicos e mutagênicos ocasionados por esse fármaco em sistema-teste vegetal reafirmando assim a importância desse alimento na nossa dieta.

O controle positivo teve a capacidade de induzir nas células vegetais parada no ciclo celular, muito provavelmente pela capacidade de induzir mutações nessas células o que ficou comprovado quando foram observados seus números de IM (Índice mitótico) e total de AC (Alterações cromossômicas), valores significantes quando comparados com o Controle negativo.

O paracetamol além de induzir mutações como quebras cromossômicas observadas nesse estudo pela formação de MN (Micronúcleos) bem como duplicações de material genético (brotos nucelares), em estudos 
de Da Silva DPB, et al., 2014, mostrou a capacidade do mesmo em elevar o número de EROS (espécies reativas de oxigênio).

Paracetamol, quando usado no co-tratamento com caju e cajuína, nos tempos analisados ( 24 e $48 \mathrm{hs}$ ), teve seus efeitos citotóxicos e mutagênicos significativamente reduzidos pelos compostos naturais. Os efeitos protetores podem ser ligados pelo alto potencial de varredura dos radicais livres do suco de caju e da cajuína, atribuídos à sua capacidade antioxidante, segundo Alves MS, et al., 2013.

Ambos os sucos contêm vários compostos fitoquímicos que são protetores contra agentes mutagênicos. Estes incluem os carotenóides, flavonóides, vitaminas e compostos fenólicos. Alguns desses compostos foram previamente quantificados, e o suco de caju é considerado uma boa fonte de fenóis $A$ capacidade antioxidante total de RCAJ ( $85 \pm 7 \mu \mathrm{M}$ Trolox / g de suco) é duas vezes maior que UNCAJ ( $45 \pm 4 \mu \mathrm{M}$ Trolox / $g$ de suco).

A triagem fitoquímica para antioxidantes específicos não enzimáticos mostrou que a RCAJ apresentou níveis significativamente mais altos de fenólicos totais (38,3 mg GAE / $100 \mathrm{~g}$ de suco), antocianinas (2,05 mg / $100 \mathrm{~g}$ de suco), flavonóides amarelos (3,92 mg / $100 \mathrm{~g}$ de suco), vitamina $C$ total ( $86,22 \mathrm{mg} / 100 \mathrm{~g}$ de suco), exceto para carotenóides $(0,39 \mathrm{mg} / 100 \mathrm{~g}$ de suco) e taninos, 0,42, 0,34, 0,37 $\mathrm{mg} / 100 \mathrm{~g}$ de suco para dímeros, oligômeros e polímeros, respectivamente (VASCONCELOS MS, et al., 2015)

Melo-Cavalcante AAC, et al. (2003) usando Salmonella typhimurium TA102 no teste de Ames, mostraram que o suco de caju e cajuína, quando co-incubados com aflatoxina B1 (AFB1), tiveram atividades antimutagênicas. Estas atividades foram associadas com o aumento da metabolização de AFB1 em compostos não mutagênicos ou com a inibição da ativação AFB1 pela união de componentes químicos com enzimas S9.

Além disso, o suco de caju e cajuína exibiu efeitos antimutagênicos contra a mutagênese oxidativa induzida por peróxido de hidrogênio em TA102, que foram associados com excelente potencial antioxidante dos sucos (MELO-CAVALCANTE AAC, et al., 2003).

Ambos os tipos de sucos tem propriedades antimutagênicas contra mutagénicos diretos como metilmethanosulfonato e 4-nitroquinolina- $\mathrm{N}$-óxido e contra mutagénicos indiretos como benzo [a] pireno, de acordo com o pré-tratamento e co-tratamento, e os ensaios de pós-tratamento com S. typhimurium TA100, TA102, e TA97. Este achado sugere que sucos de caju frescos ou transformados podem proteger as células contra a mutagênese induzida por agentes mutagênicos diretos e indiretos (MELO-CAVALCANTE AAC, et al., 2008).

Nos resultados desse presente estudo, o suco de caju e cajuina não conduziram ao aumento no dano do DNA, pelo contrário, quando os mesmos em co-tratamento com o paracetamol (CP) tiveram a capacidade de reduzir significantemente as AC (alterações cromossômicas) em ambos os tempos analisados 24 e $48 \mathrm{~h}$ (Figura 3 e 4 ). 
Figura 3 - Atividade antimutagênica do suco do caju e cajuína quando administrado juntamente com um CP utilizado em sistemas testes vegetais com TE 24h.

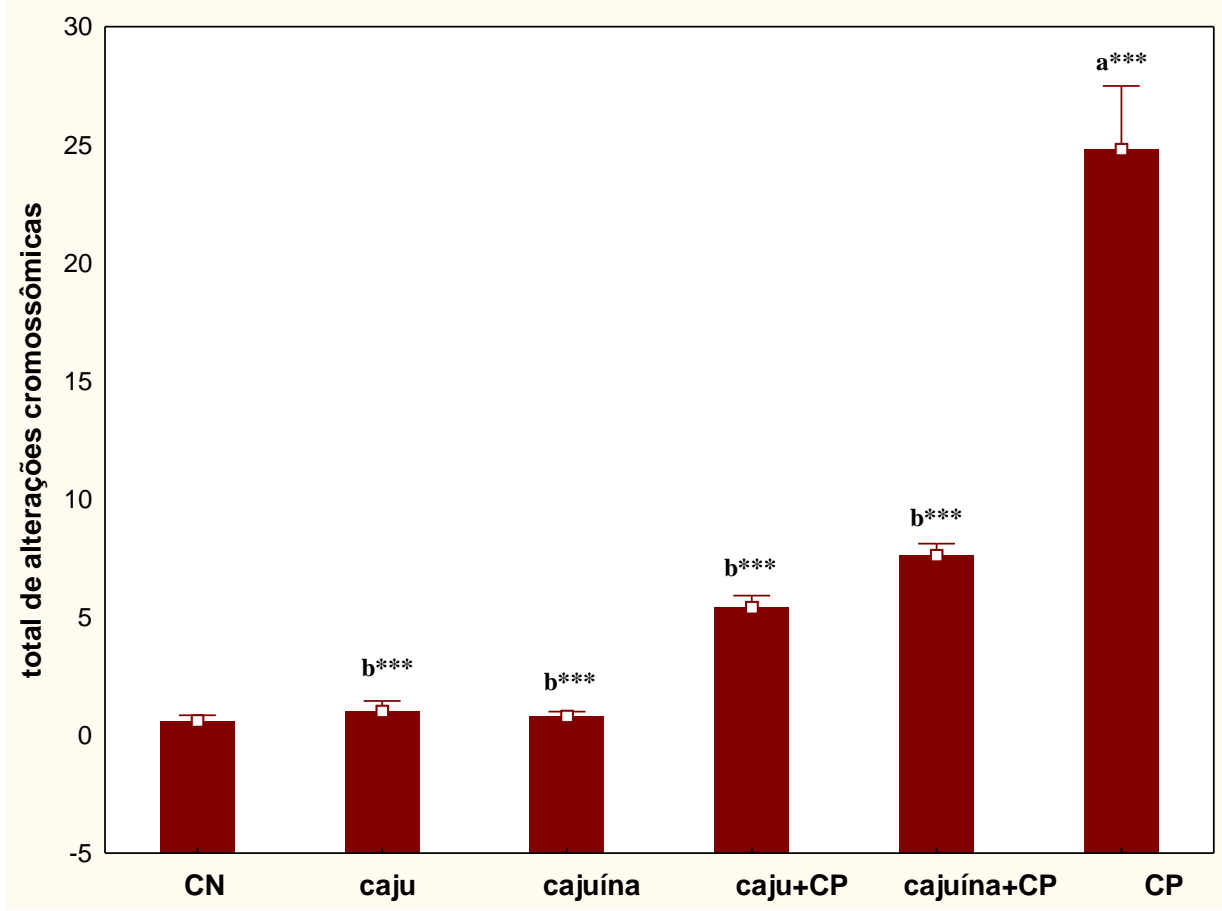

Legenda: CN - Controle negativo; CP - Controle Positivo. ANOVA unifatorial, com Pós-teste de Fisher LSD. a: Significante comparado com $C N,{ }^{* \star *} p<0,001$. b: Significante comparado com $C P,{ }^{* *} p<0,0$.

Fonte: Santos FIS, et al., 2019.

Figura 4 - Atividade antimutagênica do suco do caju e cajuína quando administrado juntamente com um CP utilizado em sistemas testes vegetais com TE 48h.

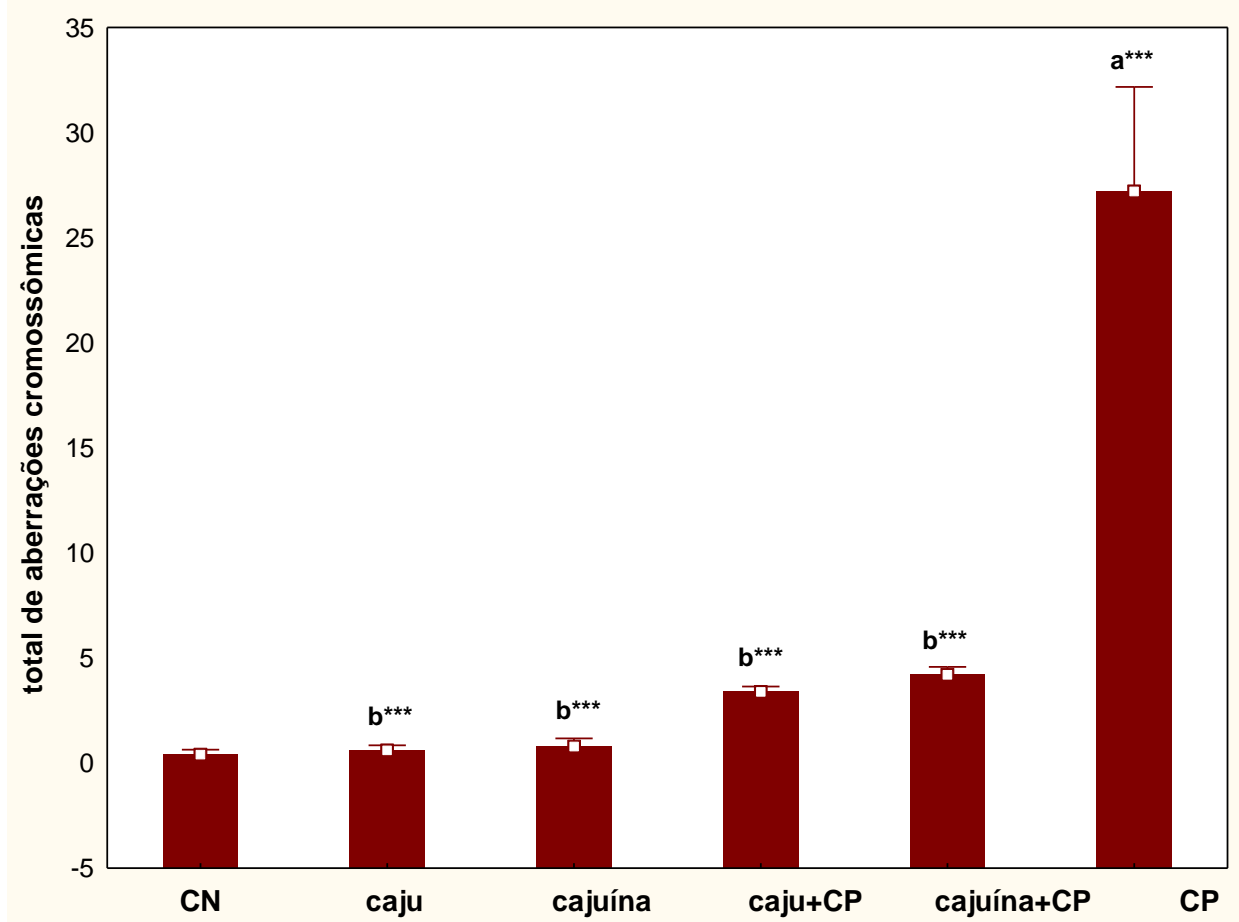

Legenda: CN - Controle negativo; CP - Controle Positivo. ANOVA unifatorial, com Pós-teste de Fisher LSD. a: Significante comparado com $C N,{ }^{* * *} p<0,001$. b: Significante comparado com $C P,{ }^{* *} p<0,01$.

Fonte: Santos FIS, et al., 2019. 
No TE (Tempo de Exposição) 24hs, o caju e a cajuina em co-tratamento tiveram a capacidade de reduzir os AC em até $81,9 \%$ e $69,7 \%$, repectivamente. Para o TE $48 \mathrm{hs}$, essas reduções foram respectivamente de $90,2 \%$ e $86,4 \%$. Se for observado o \%R (porcentagem de redução de AC), o suco de caju se mostrou mais eficiente em relação aos efeitos antimutagênicos em comparação ao suco de caju processado (cajuína) (Tabela 2).

Tabela 2 - Efeitos antimutagênicos do Co-Tratamento com Paracetamol e Suco de caju ou Cajuína em células meristemáticas de Allium cepa em $24 \mathrm{~h}$ e $48 \mathrm{~h}$.

\begin{tabular}{|c|c|c|c|c|c|}
\hline Tratamento & TE & $\begin{array}{l}\text { Total de células } \\
\text { analisadas }\end{array}$ & Média \pm DP & Frequência (\%) & $\% R$ \\
\hline $\mathrm{CN}$ & & 5000 & $0,6 \pm 0,55$ & $0,06 \%$ & - \\
\hline Caju & & 5000 & $1 \pm 1^{b^{* * *}}$ & $0,1 \%$ & - \\
\hline Cajuína & & 5000 & $0,8 \pm 0,45^{b^{\star \star \star}}$ & $0,08 \%$ & - \\
\hline Caju + CP & $24 \mathrm{~h}$ & 5000 & $5,4 \pm 1,14^{b^{* * *}}$ & $0,5 \%$ & $81,9 \%$ \\
\hline $\begin{array}{l}\text { Cajuína + } \\
\text { CP }\end{array}$ & & 5000 & $7,6 \pm 1,144^{b^{* * *}}$ & $0,8 \%$ & $69,7 \%$ \\
\hline $\mathrm{CP}$ & & 5000 & $24,8 \pm 6,02^{\mathrm{a}^{\star * *}}$ & $2,5 \%$ & - \\
\hline $\mathrm{CN}$ & & 5000 & $0,4 \pm 055$ & $0,04 \%$ & - \\
\hline Caju & & 5000 & $0,6 \pm 0,55^{b^{* * *}}$ & $0,06 \%$ & - \\
\hline Cajuína & & 5000 & $0,8 \pm 0,84^{b^{* * *}}$ & $0,08 \%$ & - \\
\hline Caju + CP & $48 \mathrm{~h}$ & 5000 & $3,4 \pm 0,544^{b^{\star \star \star}}$ & $0,3 \%$ & $90 \%$ \\
\hline $\begin{array}{l}\text { Cajuína }+ \\
\text { CP }\end{array}$ & & 5000 & $4,2 \pm 0,84^{b^{\star \star \star}}$ & $0,4 \%$ & $86,4 \%$ \\
\hline $\mathrm{CP}$ & & 5000 & $27,2 \pm 11,1^{\mathrm{a}^{* \star *}}$ & $2,7 \%$ & - \\
\hline
\end{tabular}

Legendado: CN - Controle negativo; CP - Controle Positivo. ANOVA unifatorial, com Pós-teste de Fisher LSD. a: Significante comparado com CN, ${ }^{* *} p<0,001$. b: Significante comparado com $C P,{ }^{* *} p<0,01$.

Fonte: Santos FIS, et al., 2019.

Isso, provavelmente, se deve ao seguinte fato, sendo a cajuína um suco processado, a clarificação e as etapas de tratamento térmico de sua produção podem remover compostos químicos ou alterar suas propriedades. Em termos de componentes presentes nos sucos, as concentrações de ácido ascórbico e de ácido anacárdico são cerca de 77 vezes e 43 vezes menor, respectivamente, em cajuína que no suco de caju (MELO-CAVALCANTE AAC, et al., 2011).

Os efeitos anticitotóxicos / antimutagênicos coordenados pelos sucos de caju e cajuína, podem representar mais de um mecanismo. A atividade anticlastogênica de compostos fenólicos presentes nos sucos em questão pode ser relativo a sua eficiência de quelar metais, do mesmo modo que para a sua ação como fonte da limpeza de radical livre (ALVES MSO, et al., 2013). Além disso, o ácido anacárdico pode danificar a produção de ânion superóxido,exercendo também como um antioxidante (ASHRAF MS, et al., 2018; DA SILVA DPB, et al., 2018). Também, há um vínculo entre as atividades antioxidantes disposto ao suco de caju e cajuína e sua performace antimutagênico.

Os componentes dos sucos (ácido anacárdico, ácido ascórbico, carotenóides, e compostos fenólicos), provavelmente interagem com os metabolitos ativos do Paracetamol. Estudos tem demonstrado que $\circ A$. occidentale reduz a frequência de aberrações cromossômicas induzidas pela doxorrubicina durante fases específicas do ciclo celular (G1, S, e G2) em culturas de células (BARCELOS GRM, et al., 2007; MELOCAVALCANTE AAC, et al., 2011).

Sabe-se que a composição fitoquímica da planta $A$. occidental apresenta compostos fenólicos, como quercetina, antocianinas e taninos. Esses compostos fitoquímicos estão relacionados a várias atividades biológicas, incluindo atividades antiapoptóticas, apoptóticas, antioxidantes e anti-inflamatórias (VISWANATH V, et al., 2016; TROX J, et al., 2010; GORLACH S; FICHNA J e LEWANDOWSKA U, 2015). 
Os efeitos antigenotóxicos e anticlastogênicos do suco de caju foram avaliados na genotoxicidade e mutagenicidade induzidas pela ciclofosfamida em camundongos suíços machos. O suco exerceu efeitos antigenotóxicos, diminuindo a frequência de micronúcleos induzidos por ciclofosfamida e danos ao DNA no sangue periférico de camundongos e de aberrações cromossômicas na medula óssea( MELO-CAVALCANTE AAC, et al., 2011).

Avaliações mutagênicas e antimutagênicas com caju congelado também foram realizadas em células eucarióticas da levedura Saccharomyces cerevisiae por Spada PDS, et al. (2008). Contudo, neste estudo, a polpa congelada mostrou atividade mutagênica em três diferentes concentrações (5, 10 e 15\%) dos locos testados de maneira dependente da dose e não exibiu atividade antimutagênica contra mutações induzidas por peróxido de hidrogênio.

Em um estudo sobre o extrato das folhas de caju em linhagens celulares de leucemia linfoblástica aguda humana, o extrato testado mostrou um possível efeito dos compostos fenólicos na membrana celular que teve a capacidade de induzir estresse oxidativo, podendo desencadear a apoptose por vias intrínsecas.

As caspases conduzem à morte celular apoptótica e são categorizadas como iniciadoras (Casp 9) ou efetoras (Casp 3). Para confirmar o potencial apoptótico do extrato, a expressão do gene caspase 3 foi avaliada em ambas as células testadas após o periodo de tempo estabalecido. Os polifenóis induziram apoptose em células de leucemia, regulando de forma dependente as vias de caspase, promovendo a superexpressão do gene caspase 3 (FOGARTY CE e BERGMANN A, 2017; SINGH S, et al., 2016).

Estudos têm mostrado que a utilização de uma mistura complexa pode ser mais vantajosa do que a utilização de compostos isolados (SERPELONI JM, et al., 2008). A interação e possíveis efeitos sinérgicos podem facilitar os efeitos protetores observados.

Todos estes compostos podem atuar em conjunto, diminuindo a metabolização do Paracetamol e aumentando a eliminação de radicais livres produzidos por este agente mutagénico. Por conseguinte, os sucos analisados poderiam proteger o DNA genómico diminuindo assim as Alterações genéticas observadas nos resultados acima.

Embora os mecanismos subjacentes à atividade anticitotóxica e antimutagênica de $A$. occidentale não sejam completamente compreendidos, a sua atividade antioxidante ou a interferência de uma ou mais das suas substâncias ativas com vias metabólicas mutagénicas pode explicar os seus efeitos sobre a mutagenicidade do Paracetamol (ZEZULKA Š, et al., 2018).

\section{CONCLUSÃO}

Os compostos bioativos estejam presentes no suco de caju e sua derivação cajuína, possuindo capacidade de inibir a formação de alterações mutagênicas, causadas pelo fármaco utilizado durante o estudo, a partir da observação do aumento do Índice Mitótico e redução das Alterações Cromossômicas. Desse modo, os testes aplicados no estudo e seus respectivos resultados, foram condizentes ao que se encontra na literatura científica acerca da atividade antioxidante do suco de caju e cajuína.

\section{SIGLAS E ABREVIAÇÕES}

\pm - Mais ou menos

$\mu \mathrm{M}$ - Micromolar

A. cepa- Allium cepa

ANOVA-AnalysisofVariance(análise de variância)

$\mathrm{cm}$ - Centímetro

$\mathrm{CN}$ - Controle negativo

$\mathrm{CP}$ - Controle positivo

g- Grama

GAE - Equivalente em ácido gálico

hs - Horas 
IM - Índice Mitódico

L - Litros

LSD - Dietilamida do Ácido Lisérgico

$\mathrm{mg}$ - Miligrama

MIPs - Medicamentos Isentos de Prescrição

$\mathrm{mL}-$ Mililítro

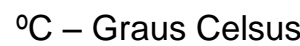

$P$ - Probabilidade

RCAJ-Suco de caju maduro

TA100 - his G46, bio chIDuvrB gal, rfa, pKM101

TA102 - his G428, rfa, pKM101, pAQ1

TA97 - his 01242, bio chIDuvrB gal, rfa, pKM101

TE - Tempo de Exposição

Trolox - Análogo solúvel em água

UNCAJ- Suco de caju verde

\section{REFERÊNCIAS}

1. ALVES MSO, et al. Compostosbioativos e atividadeantioxidante de pseudofrutos de cajuarbóreo do Cerrado. Revista do Instituto Adolfo Lutz, 72(4); 327-331, 2013.

2. ASHRAF MS, RATHINASAMY K. Antibacterial and anticancer activity of the purified cashew nut shell liquid: Implications in cancer chemotherapy and wound healing. Natural product research, 32(23); 2856-2860, 2018.

3. BARCELOS GRM, et al. Evaluation of mutagenicity and antimutagenicity of cashew stem bark methanolic extract in vitro. J Ethnopharmacol, 114(2); 268-273, 2007.

4. DA SILVA DPB, et al. Chemical characterization and pharmacological assessment of polysaccharide free standardized cashew gum extract (Anacardiumoccidentale L.). Journal of ethnopharmacology, 213; 395-402, 2018.

5. FIRBAS $P, A M O N$ T. Allium chromosome aberration test for evaluation effect of cleaning municipal water with Constructed Wetland (CW) in SvetiTomaž, Slovenia. J BioremedBiodegrad, v. 4, n. 4, p. 189-193, 2013.

6. FOGARTY CE, BERGMANN A. Killers creating new life: caspases drive apoptosis-induced proliferation in tissue repair and disease. Cell Death \& Differentiation, v. 24, n. 8, p. 1390-1400, 2017.

7. FREITAS JAB, et al. Medicamentos isentos de prescrição: perfil de consumo e os riscos tóxicos do paracetamol. Revinter, 10(3); 134-154, 2017.

8. GORLACH S, Fichna J, Lewandowska U. "Polyphenols como drogas anticâncer direcionadas às mitocôndrias", Cancer Letters , v. 366, n. 2, p. 141-149, 2015.

9. GUERRA M, SOUZA MJ. Como observar os cromossomos: um guia de técnicas em citogenética vegetal, animal e humana. Preto Ribeirão Preto: Editora FUNPEC. 132; 2002.

10. LIMAN R. Genotoxic effects of Bismuth (III) oxide nanoparticles by Allium and Comet assay. Chemosphere, v. 93, n. 2, p. 269-273, 2013.

11. MAITI S, et al. Analysis of cytotoxicity and genotoxicity on E. coli, human blood cells and Allium cepa suggests a greater toxic potential of hair dye. Ecotoxicology and environmental safety, v. 124, p. 248-254, 2016.

12. MELO- CAVALCANTE AA, et al. Mutagenicity, Antioxidant Potencial, and Antimutagenic Activity Against Hydrogen Peroxideof Cashew (Anacardiumoccidentale) Apple Juicean da Cajuína. Environmental and Molecular Mutagenesis, 41(5); 360-369, 2003.

13. MELO-CAVALCANTE AA, RUBENSAM G, PICADA JN. Mutagenicidade, antioxidante e antimutagênica atividade contra hidrogênioperóxido de caju (Anacardium occidentale) de suco de maçã e cajuína. Ambiente Mol Mutagen, 41:360-369, 2003.

14. MELO-CAVALCANTE AAC, et al. Atividade antimutagênica de caju (Anacardium occidentale Sapindales, Anacardiaceae) suco fresco e processadosuco (cajuı'na) contra methylmethanesulfonate, 4 nitroquinolinaN-óxido e o benzo [a] pireno. Genetic Mol Biol, 31; 759 -766, 2008.

15. MELO-CAVALCANTE AAC, et al. In vivo antigenotoxic and anticlastogenic effects of fresh and processed cashew (Anacardiumoccidentale) apple juices. Journalof medicinal food, 14(7-8):792-798, 2011.

16. MELO-CAVALCANTE AAC, et al. In vivo antigenotoxic and anticlastogenic effects of fresh and processed cashew (Anacardiumoccidentale) Apple Juices. J Med Food, 14(8); 792-798, 2011.

17. MELO-CAVALCANTE AAC. Caju (Anacardium ocidentale) maçã reduz mutagenicidade de aflatoxina B1 em S. typhimurium TA102. GenéticoMolBiol, 28; 328-333, 2005.

18. MENEGUETTI DUO, et al. Análise Citotóxica e Mutagênica do Extrato Aquoso de MaytenusguyanensisKlotzschExReissek (Celastraceae) Chichuá (Xixuá) Amazônico. Ciência e Natura, 36(3); 301309, 2014.

19. PEREIRA FGF, et al. Conhecimento e comportamento autorreferidos sobre descarte domiciliar de medicamentos. J. res. fundam. care, 11(1); 154-159, 2019. 
20. PIRES AM, et al. Microbial production of hyaluronic acid from agricultural resource derivatives. Bioresour Technol, 101(16); 6506-6509, 2010.

21. PORTIS IG, et al. Bioensaiocitogenético para a caracterização da mutagenicidade e citotoxicidade da espécie Choclhospermumregium. Revista Eletrônica da Faculdade de Ceres, 5(1); 1-22, 2016.

22. REGO SC, et al. Avaliação da toxicidade, citotoxicidade, mutagenicidade e genotoxicidade da dipirona sódica e do paracetamol em células meristemáticas de raízes de Allium cepa. Boletim Informativo Geum. 6 (4); 7-15, 22015.

23. SERPELONI JM, et al. Avaliação in vivo da anticlastogenicidade de extratos de plantas medicinais do gênero Miconia através do teste do micronúcleo. Semina: Ciências Biológicas e da Saúde. 29 (1); 47-56, 2008.

24. SILVA FDB, et al. Potencial citotóxico, genotóxico e citoprotetor de extratos aquosos de CaesalpiniapyramidalisTul.,Caesalpiniaferrea Mart. eCaesalpiniapulcherrimaSw. Revista Brasileira de Biociências. 13(2); 101-109, 2015.

25. SINGH S, et al. Lead phytochemicals for anticancer drug development. Frontiers in plant science, v. 7, p. 1667, 2016.

26. SOCIEDADE BRASILEIRA DE ALIMENTOS FUNCIONAIS. 2007. Disponível em: http://www.sbaf.org.br. Acesso em: 23 dezembro de 2015.

27. SPADA PDS, et al. Antioxidant, mutagenic, and antimutagenic activity of frozen fruits. Journal of Medicinal Food, v. 11, n. 1, p. 144-151, 2008.

28. STEFANELLO S, et al. Levantamento do uso de plantas medicinais na Universidade Federal do Paraná, Palotina PR, Brasil. Revista Extensão em Foco. 1(15); 15-27, 2018.

29. TROX J, et al. "(Anacardium occidentale I) compostos bioactivos em kernels de castanha de caju: Efeito de diferentes métodos de descasque, " Journal of Agricultural and Food Chemistry , v. 58, n. 9, p. 5341-5346, 2010.

30. VASCONCELOS MS, et al. Anti-inflammatory and wound healing potential of cashew apple juice (Anacardiumoccidentale L.) in mice. Experimental Biologyand Medicine. 240 (12); 1648-1655, 2015.

31. VIEIRA AL, et al. As consequências no consumo indiscriminado do paracetamol e orientação farmacêutica à promoção ao uso racional. RevistaAcadêmica Oswaldo Cruz. 6 (6); 1-12, 2015.

32. VISWANATH V, et al. "Propriedades térmicas do tanino extraído de Anacardium occidentale L. usando espectroscopia TGA e FT-IR", Natural Product Research , v. 30, n. 2, p. 223-227, 2016.

33. ZEZULKA Š, et al. Sensibilidade de parâmetros fisiológicos e bioquímicos em estádios ontogenéticos iniciais de cultivos sob tratamento com diclofenaco e paracetamol. Ciência Ambiental e Pesquisa sobre Poluição. 1-15, 2018. 